\title{
Treatment of Synthetic Produced Water using Hybrid Membrane Processes
}

\author{
N. Chin, S. O. Lai*, K. C. Chong, S. S. Lee, C. H. Koo \& H. S. Thiam \\ Lee Kong Chian Faculty of Engineering and Science, Universiti Tunku Abdul \\ Rahman, Jalan Sungai Long, Bandar Sungai Long, Kajang 43300, Malaysia \\ Submitted: 6/10/2018. Revised edition: 7/11/2018. Accepted: 12/11/2018. Available online: 21/11/2018
}

\begin{abstract}
The study was concerned with the treatment of tank dewatering produced water using hybrid microfiltration (MF) and ultrafiltration (UF) processes. The pre-treatment MF membrane was fabricated with polyethersulfone (PES), n-methyl-2-pyrrolidone (NMP) and polyvinylpyrrolidone (PVP). The UF membranes meanwhile contained additional component, i.e., titanium dioxide $\left(\mathrm{TiO}_{2}\right)$ nanoparticles in the range of zero to $1.0 \mathrm{wt} . \%$. The membrane performances were analysed with respect to permeate flux, oil removal and flux recovery ratio. An increase in $\mathrm{TiO}_{2}$ nanoparticles enhanced the pore formation, porosity and pure water permeability due to improved hydrophilicity. The permeate flux of UF membranes increased with the increase of $\mathrm{TiO}_{2}$ nanoparticles and pressure. The oil removal rate by MF process was only $52.35 \%$, whereas the oil rejection efficiency was between $82.34 \%$ and $95.71 \%$ for UF process. It should be highlighted that the overall oil removal rate could achieve as high as 97.96\%. Based on the results, the PES membrane incorporated with $1.0 \mathrm{wt} . \% \mathrm{TiO}_{2}$ was proved to be the most promising membrane at a transmembrane pressure of 3 bar. Although $1.0 \mathrm{M} \mathrm{NaOH}$ solution could be used as cleaning agent to recover membrane water flux, it is not capable of achieving good results as only $52.18 \%$ recovery rate was obtained.
\end{abstract}

Keywords: Produced water treatment, microfiltration, ultrafiltration, permeate flux, oil removal

\subsection{INTRODUCTION}

Oily wastewater is defined as the combination of wastewater and oil under different concentrations [1]. It is usually produced in several industries, including oil refinery, petrochemical, metallurgy, automotive, machinery, food and beverage [2, 3]. The largest byproduct or waste stream generated in the oil and gas industry is known as produced water or oilfield brine. Produced water is a composite of organic and inorganic components which mainly involves the dissolved and dispersed oil compounds, dissolved formation minerals, production chemicals, produced solids as well as the dissolved gases [4].
An increase in the production of oily wastewater leads to a major environmental issue. The discharge of oily wastewater directly from the industries without adequate treatment will result in various types of pollution by contaminating groundwater resources, endangering health of living creatures and even deconstructing natural landscapes [5]. Therefore, the processes of separating oil droplets from wastewater have gained extensive interests, so that the treated water which meets regulatory standards can be reused in other fields.

The treatment of oily wastewater can be conducted either in physical, chemical or biological route, depending on the types and quantities

\footnotetext{
* Corresponding to: S. O. Lai (email: laiso@utar.edu.my)
} 
of pollutants as well as the respective allowable level of specific contaminants [3]. The are several types of conventional technology, namely flotation, coagulation, flocculation, centrifugal settling, chemical emulsification and biological treatment [6]. These methods have shown the similarity in disadvantages and limitations. For example, tiny oil droplets are remained in the filter water owing to low oil removal efficiency. Besides, high capital and operating costs are required to maintain proper functioning of the separation systems.

Consequently, many research institutions have investigated in-depth and they have reported on the efficient and feasible alternatives to treat oily wastewater. Membrane-based technology are concluded to be the promising methods in the treatment of stable emulsified oily wastewater [7, 8]. Among all the membrane-based processes, microfiltration (MF) and ultrafiltration (UF) receive additional attention. These membrane filtration systems able to overcome the limitations of conventional technology by providing several advantages such as a straightforward operation, stable quality of effluent, high selectivity and high oil removal efficiency as well as low operating investment [9]. Moreover, the outcomes of the treatment of oily wastewater are satisfied because the treated water after MF and UF processes is almost freeof-oil and meets the environmental standards.

The common materials used to fabricate membranes for oily wastewater separation processes are polymer and ceramic. Polymeric membrane is a synthetic membrane which has better oil rejection efficiency compared to organic membrane. On the other hand, ceramic membranes are mainly made from clays of nitrides and metal oxides [4].

The researchers studied the intrinsic property of polymeric membranes and concluded that these oleophilic membranes had to be modified with hydrophilic additives during phase inversion process in order to avoid adhesion of oily particles on the membrane surfaces [10]. This is because hydrophobic membranes such as PVDF and PES usually foul more than hydrophilic surface [11].

Membrane fouling becomes a major barrier to hinder the separation performance of the filtration system for oily wastewater treatment. The contaminants usually accumulate on the membrane surface with prolonged filtration duration, resulting in decline of permeate flux and oil retention efficiency as well as the lifespan of the membrane [12]. The fouled membranes can be cleaned in either physical or chemical method, depending on the condition of fouling membrane and the types of foulants.

\subsection{METHODS}

\subsection{Materials}

Polyethersulfone (PES) and n-methyl2-pyrrolidone (NMP) purchased from EMPLURA $\circ$, R were used as the major membrane forming material and solvent, respectively. Polyvinylpyrrolidone (PVP) obtained from R\&M Chemicals was chosen as the additive to act as pore former, whereas the other additive was titanium dioxide $\left(\mathrm{TiO}_{2}\right)$ nanoparticle from R\&M Chemicals.

Sodium sulfate anhydrous obtained from DUKSAN was used as inert drying agent, whereas n-hexane 
purchased from EMSURE $\circ, \mathrm{R}$ was used as oil extraction solvent. Sodium hydroxide from EMSURE $\circ$, R was used as the cleaning agent.

\subsection{Preparation of Membrane Dope Solutions}

The dope solutions consisted of PVDF, NMP, PVP and $\mathrm{TiO}_{2}$. In this study, one MF membrane was fabricated due to its function of pre-treating the feed solution whereas four UF membranes were fabricated with different compositions. The compositions of five respective sets of membrane dope solutions were summarised in Table 1.

Table 1 Compositions of membrane dope solutions

\begin{tabular}{lccll}
\hline \multirow{2}{*}{ Sample } & \multicolumn{4}{c}{ Composition (wt. \%) } \\
\cline { 2 - 5 } & PES & NMP & PVP & TiO $_{2}$ \\
\hline M1 & 12 & 84.0 & 4 & 0 \\
U1 & 16 & 83.0 & 1 & 0 \\
U2 & 16 & 82.9 & 1 & 0.1 \\
U3 & 16 & 82.5 & 1 & 0.5 \\
U4 & 16 & 82.0 & 1 & 1.0 \\
\hline
\end{tabular}

For MF membrane (M1), the compositions of PES, NMP and PVP were 12,84 and 4 wt.\% respectively, whereas the additive particle was not added into dope solution of M1. However, for UF membranes, the composition of pore forming additive, PVP was set as a constant value of one weight percent throughout the experiments. Meanwhile, the polymer loading remained constant at 16 wt. $\%$. Therefore, the characteristics of UF membranes were unique by varying the composition of pore forming additive and solvent. The UF dope solutions or membranes were named as U1, U2, U3 and U4, indicating different compositions of $\mathrm{TiO}_{2}$ ranging from 0 to 1 wt.\%. Lastly, the solvent, NMP would hold the remaining composition of dope solution, achieving a total composition of $100 \mathrm{wt} . \%$.

By knowing the composition of membrane dope solution, the preparation of a homogenous UF dope solution was started by drying the PES pellets overnight in an oven at a temperature of $50{ }^{\circ} \mathrm{C}$ to reduce the moisture content. The dried PES pellets were then added into correspond amount of NMP solvent. Subsequently, one weight percent of PVP and pre-weighed correspond amount of $\mathrm{TiO}_{2}$ particles were added into the mixture to produce the dope solution. The mixture was then stirred agitation at $600 \mathrm{rpm}$ and was heated at $50{ }^{\circ} \mathrm{C}$ for approximately four hours in order to obtain a completely-dissolved dope solution. Finally, the dope solution was placed in a ultrasonication probe for thirty minutes so that the air bubbles trapped in the solution were completed removed.

\subsection{Preparation of Flat Sheet Membrane}

The method used in membrane fabrication process was known as phase inversion technique whereby the solvent and non-solvent would exchange with each other [13]. The well-mixed dope solution was poured and was spread evenly over the smooth surface of a clean glass plate. Subsequently, a casting knife was used to cast the membrane with a thickness of $200 \mu \mathrm{m}$. The polymer film was then immersed into the coagulation bath which filled with distilled water. The phase inversion process was said to be carried out completely when the membrane flat sheet was stripped off from the plate. 


\subsection{Preparation of Synthetic Produced Water}

The synthetic produced water was collected by i-Chem Solution Sdn. Bhd. from a tank depot cleaning company. The company was involved in oil and gas industry and the wastewater from tank cleaning was known as tank dewatering produced water.

\subsection{Membrane Characterization}

\subsubsection{Scanning Electron Microscope}

Prior to the analysis, the membranes were immersed into liquid nitrogen and were fractured to obtain ideal cut structure. The membranes were then sputter coated with gold by using a sputter coater (Model: SC7620, Emitech). The morphological structures of the membranes such as surface and cross section micrographs images were then analysed by scanning electron microscope (SEM) (Model: S3400, Hitachi). The focal lengths used were unique for each specimen and the applied voltage was set at $15.0 \mathrm{kV}$.

\subsubsection{Energy-dispersive $\quad X$-ray Spectroscopy}

Energy-dispersive X-ray Spectroscopy (EDX) was an analysis technique used simultaneously with SEM to determine the compositions of existing components in the fabricated membranes and the distribution of $\mathrm{TiO}_{2}$ additive. The membrane sample was cut into small pieces and the active layer on the membrane surface was examined by EDX.

\subsubsection{Fourier Transform Infrared Spectrometer}

Fourier Transform Infrared Spectrometer (Model: Nicolet iS10,
Thermo Scientific) was used to detect the functional groups of the fabricated membranes. After cleaning the specimen holder with alcohol, the background spectrum was collected. The membrane specimen, which was cut into a tiny piece, was placed on the specimen holder for FTIR analysis by taking the spectrum of single-beam sample. The spectrum of the specific sample was obtained from the ratio of the spectrum of single-beam sample to background spectrum.

\subsubsection{Membrane Porosity}

The weight of wet membrane was first measured by using an analytical weight balance before the 24-hour drying process. The weight of dry membrane was then measured in order to obtain the membrane porosity. The measurement was repeated for three times and the average value was recorded for each membrane sample. The membrane porosity was calculated by dividing the total volume of the porous membrane from the pore volume as shown in Eq. (1) [7].

$\varepsilon=\frac{\frac{\left(w_{w e t}-w_{d r y}\right)}{\rho_{w}}}{\frac{\left(w_{w e t}-w_{d r y}\right)}{\rho_{w}}+\frac{w_{d r y}}{\rho_{p}}} \times 100 \%$

where $\varepsilon$ is the membrane porosity (\%), $w_{\text {wet }}$ is the weight of wet membrane (g), $\quad w_{d r y}$ is the weight of dry membrane $(\mathrm{g}), \rho_{w}$ is the density of water $\left(\mathrm{g} / \mathrm{cm}^{3}\right)$, and $\rho_{p}$ is the density of polymer $\left(\mathrm{g} / \mathrm{cm}^{3}\right)$.

\subsubsection{Mean Pore Radius}

Guerout-Elford-Ferry equation was used to compute the mean pore radius by the mean of filtration velocity method as shown in Eq. (2) [14].

$r_{m}=\sqrt{\frac{(2.9-1.75 \varepsilon) 8 \eta l Q}{\varepsilon A \Delta P}}$ 
where $r_{m}$ is the mean pore radius $(\mathrm{m})$, $\varepsilon$ is the membrane porosity (\%), $\eta$ is the viscosity of water $(\mathrm{Pa} \square \mathrm{s}), l$ is the thickness of membrane $(\mathrm{m}), Q$ is the volume of permeate water per unit time $\left(\mathrm{m}^{3} / \mathrm{h}\right), \quad A$ is the effective membrane area $\left(\mathrm{m}^{2}\right)$, and $\Delta P$ is the transmembrane pressure $(\mathrm{Pa})$.

\subsubsection{Pure Water Flux}

This test was conducted after filling the stirred cell (Model: HP4750, Sterlitech) with $300 \mathrm{~mL}$ of distilled water. The pre-cut MF membrane (M1) was pressurized with distilled water at the pressure of 1 bar. The time required to obtain $100 \mathrm{~mL}$ of pure water permeate was measured and was recorded. Subsequently, the water permeate flux was then computed by Eq. (3) [7].

$J_{w}=\frac{Q_{w}}{A \times t}$

where $J_{w}$ is pure permeate flux $\left(\mathrm{L} /\left(\mathrm{m}^{2} \square \mathrm{h}\right)\right), Q_{w}$ is the quantity of pure water permeate $(\mathrm{L}), A$ is the effective membrane area $\left(\mathrm{m}^{2}\right)$, and $t$ is the time required to obtain $100 \mathrm{~mL}$ of pure water permeate $(h)$.

\subsection{Filtration Experiment}

The experimental apparatus of the dead-end membrane system included a pressurized cylinder filled with nitrogen gas, a pressure regulator, a stirred cell (Model: HP4750, Sterlitech) and a magnetic stirrer. A scheme of the experimental set up is shown in Figure 1. The nitrogen gas was used to pressurize the feed solution (either distilled water or synthetic produced water) and to maintain the pressure gradient across the membrane. The stirred cell was continuously stirred on the magnetic stirrer at $680 \mathrm{rpm}$ in order to provide a shear force to reduce the solid cake built up on the membrane surface.

The fabricated membrane (M1) was cut into tiny round pieces with the area of $14.6 \mathrm{~cm}^{2}$. The solution was then forced through M1 at the pressure of 2 bar. After the filtration process, the permeate was collected and the volume of permeate was measured by the measuring cylinder. The permeate was then recycled to the stirred cell for UF process. The steps for UF process are similar to the MF module but the membrane inside the stirred cell was changed to UF membrane (U1) and the operating pressure was altered between 3 and 6 bar with an interval of 1 bar. While maintaining the MF process, the whole experiments were repeated with different UF membranes (U2, U3 and U4).

The volume of permeate collected was measured every five minutes until $100 \mathrm{~mL}$ of permeate was collected. Subsequently, the oil permeate flux was then computed by Eq. (4) [7].

$J_{p}=\frac{Q_{p}}{A \times t}$

where $J_{p}$ is oil permeate flux $\left(\mathrm{L} /\left(\mathrm{m}^{2} \mathrm{~h}\right)\right), Q_{p}$ is the quantity of oil permeate $(\mathrm{L}), A$ is the effective membrane area $\left(\mathrm{m}^{2}\right)$, and $t$ is the time required to obtain $100 \mathrm{~mL}$ of oil permeate $(h)$.

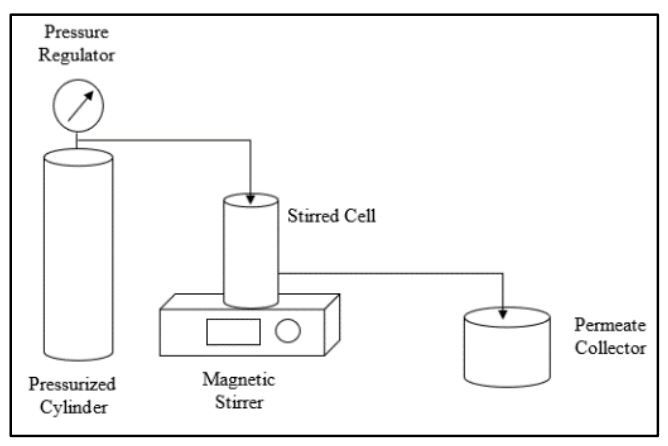

Figure 1 Schematic diagram of dead-end filtration system 
The measurement of oil concentration was conducted through partitiongravimetric method [15]. Firstly, one hundred millimetres of oil permeate was first collected in a beaker. Four millimetres of $37 \%$ hydrochloric acid was then added drop by drop into the oil permeate. The solution was mixed well and was tested with a $\mathrm{pH}$ meter to ensure the maximum of $\mathrm{pH} 2$ was achieved to hydrolysed oil and grease. The mixture was then poured into 500 $\mathrm{mL}$ separatory funnel. Ten millimetres of n-hexane solvent was added into the separatory funnel for the first oil extraction. The separatory funnel was stoppered and was inverted in order to release the gas through the stopcock. The funnel was then vigorously shaken for two minutes until no more gas escaped. The gas was released at the stopcock every thirty seconds to prevent high pressure accumulates at the end of the stopper.

The separatory funnel was left to stand undisturbed for approximately ten minutes to ensure a perfect separation between the lower water layer and upper solvent layer. The water layer was slowly drained from the separatory funnel into a beaker. Several drops of solvent were allowed to drain into the water layer to ensure complete transfer of the water layer. The glass funnel was then put in the neck of the conical flask. A piece of filter paper was folded and was put on the glass funnel before adding $5 \mathrm{~g}$ of anhydrous sodium sulphate to the filter paper. The solvent was drip-drained into the conical flask through the glass funnel. The sodium sulphate which mixed with the solvent on the filter paper was gently stirred by a glass rod when the solvent layer was draining.

The water layer collected in the beaker was poured into the separatory funnel. The second and third oil extractions were carried out to ensure the oil content was extracted out completely. Subsequently, the separatory funnel was rinsed with 5 $\mathrm{mL}$ of $\mathrm{n}$-hexane to remove any residual oil left on the funnel walls.

For the measurement of oil concentration, the solvent collected in the conical flask was poured into a 100 $\mathrm{mL}$ beaker which had been weighed beforehand. After completely evaporation of solvent, the oil content was retained in the beaker. The weight of the beaker containing residual oil was then measured. The oil concentration was calculated by using Eq. (5).

$C=\frac{m_{o}-m_{b}}{Q}$

where $C$ is the oil concentration $(\mathrm{mg} / \mathrm{L}), m_{o}$ is the mass of oil and beaker $(\mathrm{mg}), m_{b}$ is the mass of plain beaker ( $\mathrm{mg}$ ), and $Q$ is the quantity of oil (L).

The oil rejection percentage was then determined through Eq. (6) [7].

$R=\left(1-\frac{C_{p}}{C_{f}}\right) \times 100 \%$

where $R$ is the oil rejection (\%), $C_{p}$ is the concentration of permeate $(\mathrm{mg} / \mathrm{L})$, and $C_{f}$ is the concentration of feed $(\mathrm{mg} / \mathrm{L})$.

For the membrane cleaning process, sodium hydroxide $(\mathrm{NaOH})$ was selected as the cleaning agent due to its capability in removing the foulants blocked within the membrane pores and on the membrane surface. There were three concentrations of $\mathrm{NaOH}$ solution $(0.1,0.5$ and $1.0 \mathrm{M})$ to be tested in this study. The durations for immersion of fouled membrane into the cleaning agent were 10, 30 and 60 minutes. After immersing the membrane into $\mathrm{NaOH}$ solution for a certain period, the distilled water was forced through the chemically-cleaned membrane and the pure water flux was 
determined again with Eq. (3). Consequently, the flux recovery ratio was calculated with Eq. (7).

$F R R=\frac{J_{w 2}}{J_{w 1}} \times 100 \%$

where $F R R$ is the flux recovery ratio $(\%), J_{w 1}$ is the initial pure water flux of fresh membrane $\left(\mathrm{L} /\left(\mathrm{m}^{2} \square \mathrm{h}\right)\right)$, and $J_{w 2}$ is the pure water flux of chemicallycleaned membrane $\left(\mathrm{L} /\left(\mathrm{m}^{2} \square \mathrm{h}\right)\right.$ ).

\subsection{RESULTS AND DISCUSSION}

\subsection{Membrane characterization}

\subsubsection{SEM}

The images of cross sectional of membranes were extracted from SEM analysis with different magnification scales and were shown in Figure 2. Most of the membranes illustrates the formation of macrovoid with loosely packed structures. The membrane typically consists of two layers, which are a dense top finger-like layer and a spongy porous support layer. The formation of these structures can be explained by the instanteous demixing of solvent and polymer during the phase inversion process. There is no apparent difference in the crosssectional structures of the PES UF membranes since the $\mathrm{TiO}_{2}$ concentration ranging from 0 wt. $\%$ until 1.0 wt. $\%$ is not significant. However, U4 membrane contains comparatively more finger-like projections because greater amount of hydrophilic $\mathrm{TiO}_{2}$ contributed in the absorption of water during the phase inversion process. The overall SEM micrographs have proved that higher nanoparticles loading increases the membrane porosity and pore size.

Based on Figure 3, the dispersion of $\mathrm{TiO}_{2}$ additives on the surface of UF membranes can be observed from SEM micrographs upon the addition of nanoparticles from $0 \mathrm{wt} . \%$ to $1.0 \mathrm{wt} . \%$. M1 membrane might be contained some impurities which caused the top surface rougher compared to others. U1 membrane surface is relatively smooth due to homogeneous mixing at the preparation phase of dope solution. The white dots shown on the Figure 3 (c), (d) and (e) indicates the incorporation of $\mathrm{TiO}_{2}$ additives. U4 membrane with the highest nanoparticles loading shows that the greater number of white dots have greater sizes due to the agglomeration of nanoparticles.

\subsubsection{EDX}

According to Tables 3 and 4 , the $\mathrm{TiO}_{2}$ nanoparticles are proved to be incorporated successfully into the polymer dope solution. For all membranes, high proportion of carbon, oxygen and sulphur are detected as the molecular structure of PES consists of these three elements.

\subsubsection{FTIR}

The FTIR results are demonstrated as transmittance percentage (\%) against wavelength $\left(\mathrm{cm}^{-1}\right)$ for the membrane as depicted in Figures 4 and 5. The FTIR test was conducted to identify the presence of PES composition in the sample specimen. The FTIR spectra shows the presence of aromatic $\mathrm{C}-\mathrm{H}$ stretch between 3000 and $3100 \mathrm{~cm}^{-1}$. Meanwhile, the $\mathrm{S}=\mathrm{O}$ stretching peaks are found between 1000 and $1200 \mathrm{~cm}^{-}$ 1 . The aromatic $\mathrm{C}-\mathrm{H}$ bending peaks are located between 680 and $900 \mathrm{~cm}^{-1}$. Therefore, the results strongly indicate the existence of PES in the membranes. The transmittance peaks 


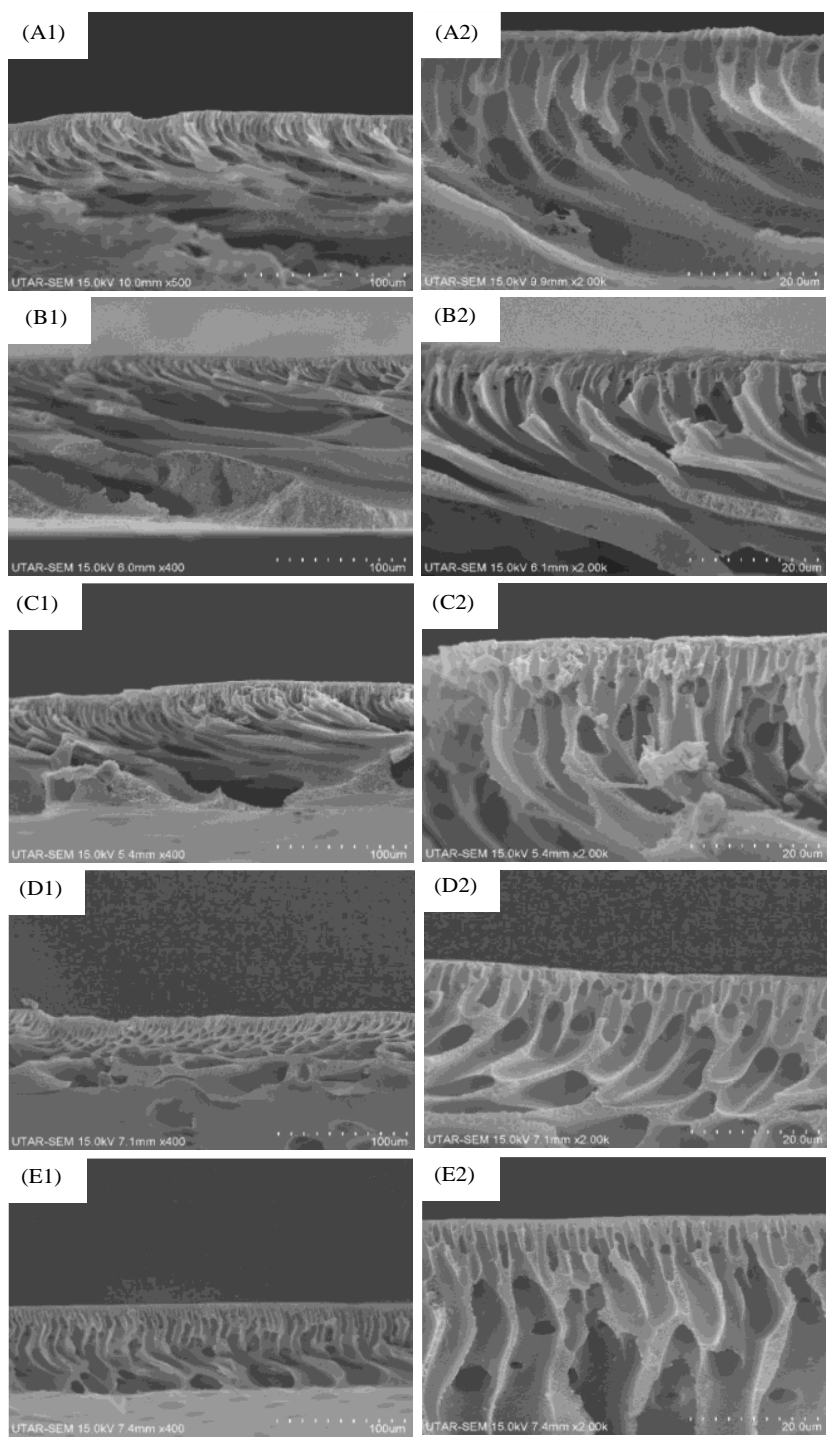

Figure 2 SEM images of cross section for membranes (A1) M1 magnified at 500x, (A2) M1 magnified at 2000x, (B1) U1 magnified at 400x, (B2) U1 magnified at 2000x, (C1) U2 magnified at 400x, (C2) U2 magnified at 2000x, (D1) U3 magnified at 400x, (D2) U3 magnified at 2000x, (E1) U4 magnified at 400x,(E2) U4 magnified at 2000x

located between 3500 and $3700 \mathrm{~cm}^{-1}$ represents the stretching peaks of $\mathrm{O}-\mathrm{H}$ functional group.

\subsubsection{Porosity and Pore Size}

The properties of PES membranes with respect to their porosity and pore size are summarized in Table 4. All fabricated membranes illustrate considerably high porosity with a minimum value of $85.26 \%$, whereby the improvement on membrane porosity is insignificant compared to other researches, where the porosity would increase drastically with the addition of $\mathrm{TiO}_{2}$ additives. In this study, the porosity and pore size of MF (M1) membrane are higher than those for UF membranes. This phenomenon is caused by the higher composition of PVP at 4 wt.\% which tends to induce mixture demixing during phase inversion process and to further enhance the phase separation. This situation is in good agreement with other research [16]. 


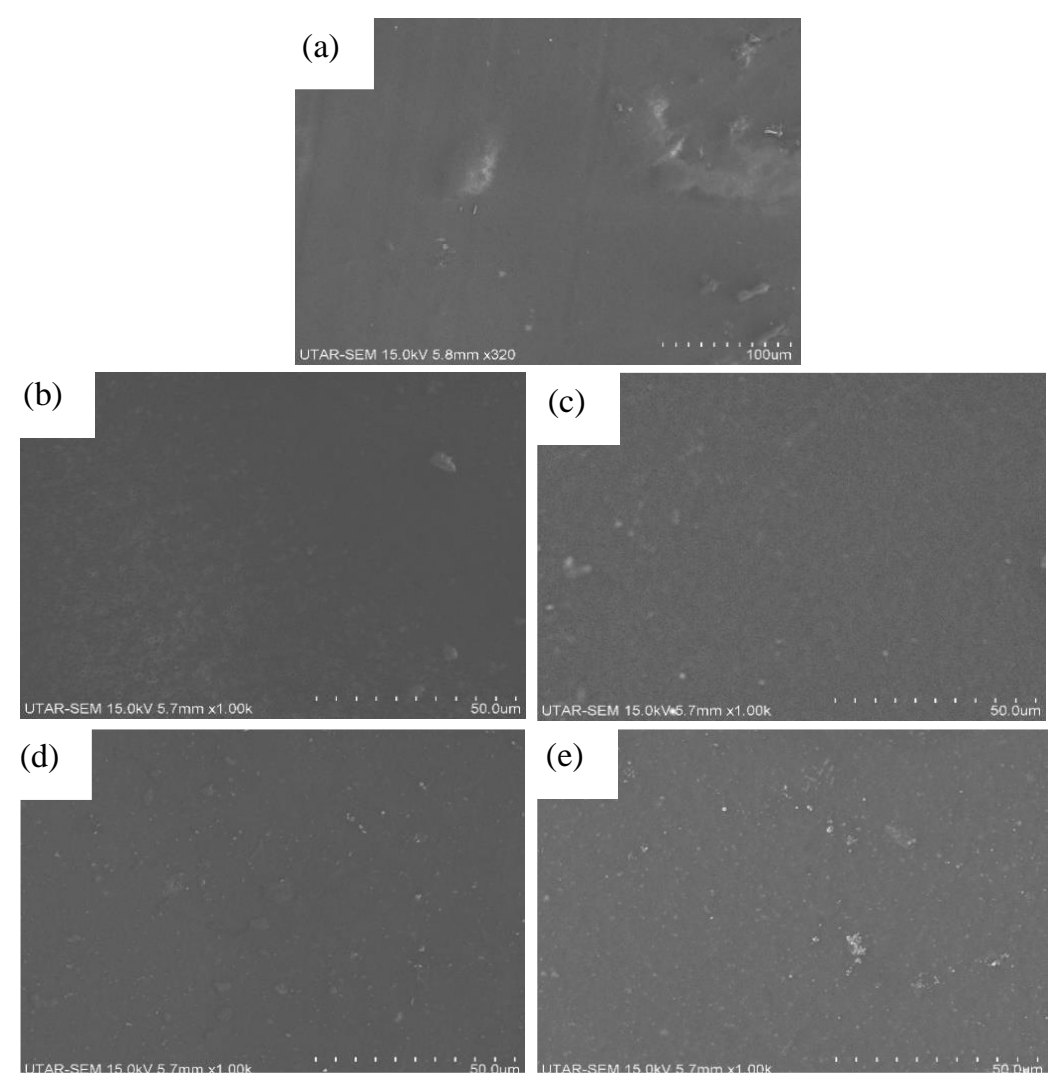

Figure 3 SEM images of surface morphology for membranes (a) M1 magnified at 320x, (b) U1 magnified at 1000x, (c) U2 magnified at 1000x, (d) U3 magnified at 1000x, (e) U4 magnified at $1000 \mathrm{x}$

Table 2 Weight percent (wt.\%) of membrane

\begin{tabular}{cccccc}
\hline \multirow{2}{*}{ Element } & \multicolumn{5}{c}{ Weight Percent (wt.\%) of Membrane } \\
\cline { 2 - 6 } & M1 & U1 & U2 & U3 & U4 \\
\hline C & 60.02 & 61.16 & 62.08 & 60.19 & 57.05 \\
$\mathbf{O}$ & 20.09 & 29.70 & 22.56 & 30.65 & 22.96 \\
$\mathbf{S}$ & 19.79 & 09.14 & 14.89 & 08.51 & 16.19 \\
$\mathbf{T i}$ & 00.11 & 00.00 & 00.46 & 00.65 & 03.80 \\
\hline
\end{tabular}

Table 3 Atomic percent (At\%) of membrane

\begin{tabular}{cccccc}
\hline \multirow{2}{*}{ Element } & \multicolumn{5}{c}{ Atomic Percent (At\%) of Membrane } \\
\cline { 2 - 6 } & M1 & U1 & U2 & U3 & U4 \\
\hline C & 72.71 & 70.40 & 73.28 & 69.54 & 70.17 \\
$\mathbf{O}$ & 18.27 & 25.66 & 20.00 & 26.59 & 21.20 \\
$\mathbf{S}$ & 08.98 & 03.94 & 06.59 & 03.68 & 07.46 \\
Ti & 00.03 & 00.00 & 00.14 & 00.19 & 01.17 \\
\hline
\end{tabular}



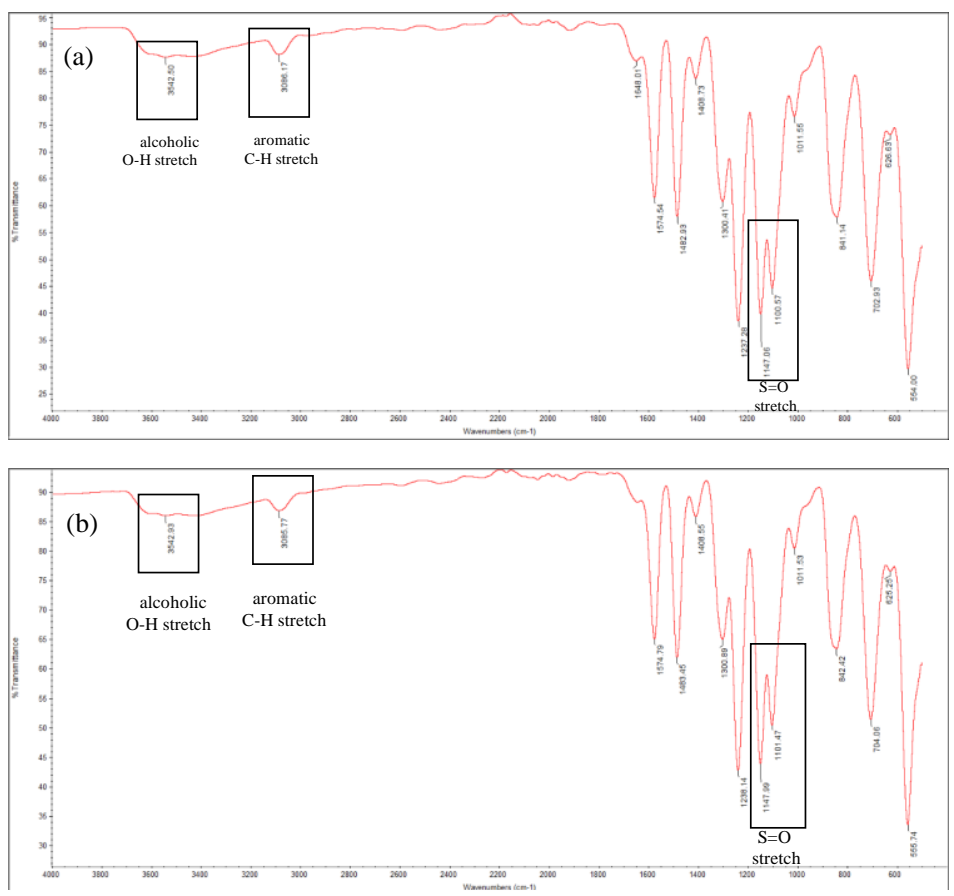

Figure 4 FTIR spectra of membranes (a) M1 and (b) U1
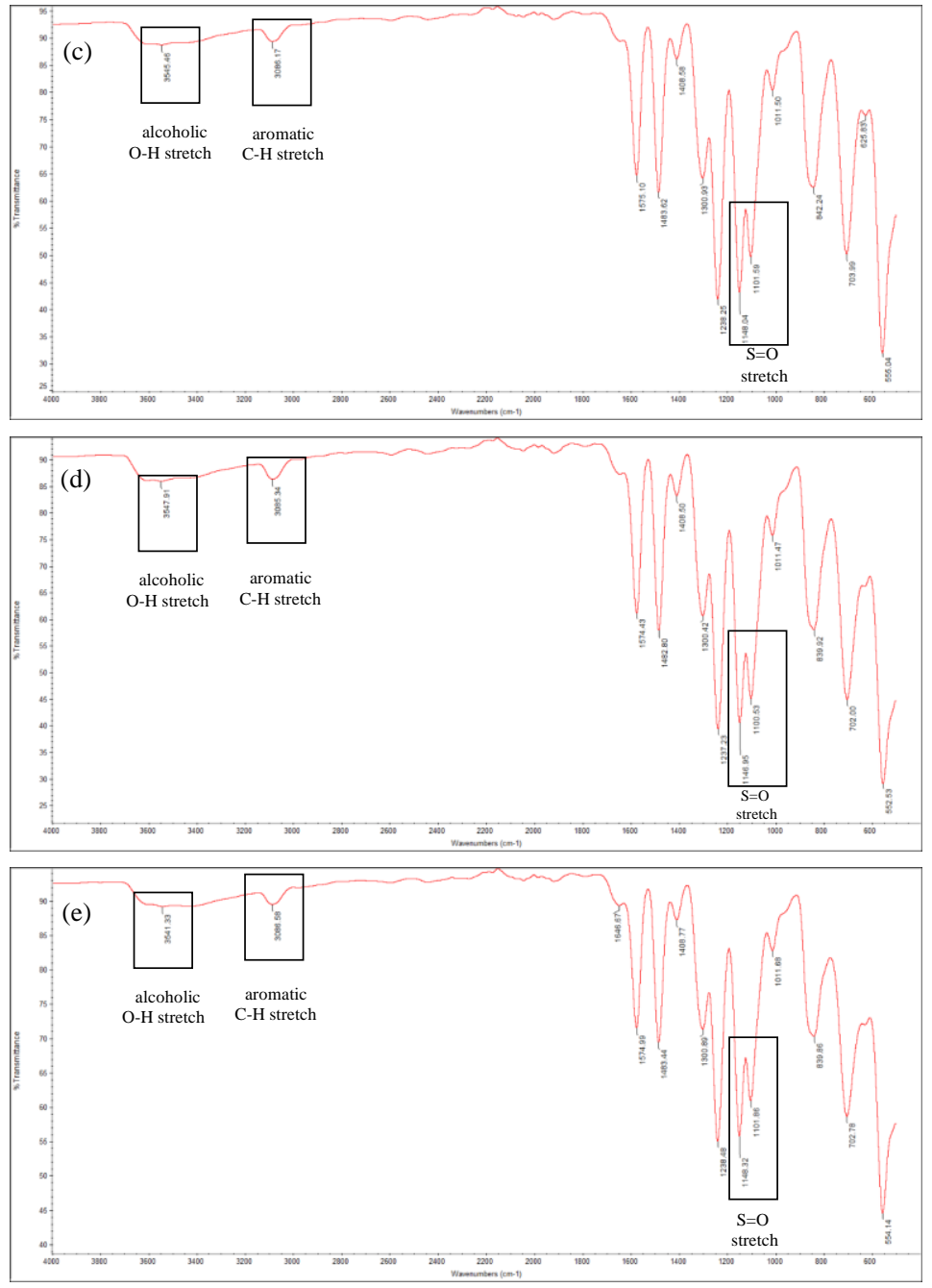

Figure 5 FTIR spectra of membranes (a) U2, (b) U3 and (c) U4 
Table 4 Porosity and pore size of membrane

\begin{tabular}{llll}
\hline Membrane & $\begin{array}{l}\text { Porosity } \\
(\boldsymbol{\%})\end{array}$ & $\begin{array}{l}\text { Pore } \\
(\boldsymbol{\mu m})\end{array}$ & Size \\
\hline M1 & 93.10 & 2.45 & \\
U1 & 85.26 & 0.071 & \\
U2 & 87.67 & 0.076 & \\
U3 & 89.26 & 0.082 & \\
U4 & 89.58 & 0.091 & \\
\hline
\end{tabular}

The average pore size is directly proportional with the membrane porosity. The calculated pore size of M1 membrane is $2.45 \mu \mathrm{m}$, which is in the range of MF membrane. For UF membranes, the pore sizes are between $0.071 \mu \mathrm{m}$ and $0.091 \mu \mathrm{m}$, which are proved to be the membranes with proper UF pore diameters. As the nanoparticles loading increases, the increment of porosity and pore size can be noticed. The presence of $\mathrm{TiO}_{2}$ tends to weaken the affinity of membrane dope solution when compared with the dope solution without nanoparticles, resulting in an increase of porosity as well as pore size. Therefore, it is suggested that addition of $\mathrm{TiO}_{2}$ nanoparticles will enhance the pore formation as supported by the SEM cross section micrographs.

\subsubsection{Pure Water Flux}

According to Figure 6, it can be seen that the permeability of M1 membrane is the highest compared with UF membranes. This is because higher composition of PVP has been added into the dope solution and PVP additive enhances the pore formation There is a huge gap between the permeability of MF membrane and UF membrane. This phenomenon is coincided with the porosities and pore sizes of membranes as presented in
Table 4. As the pore sizes of UF membranes are relatively small, less amount of water is allowed to pass through the membranes.

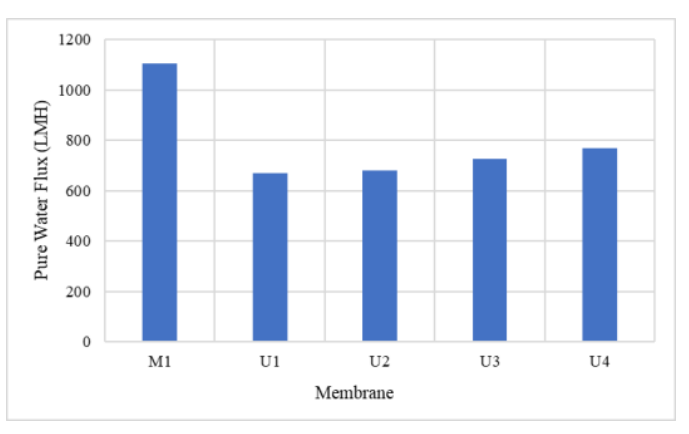

Figure 6 Pure water flux of membrane at 1 bar

For UF membranes, the pure water flux is ranging between $668.82 \mathrm{LMH}$ and $768.15 \mathrm{LMH}$. The increasing trend of permeability can be explained by the addition of $\mathrm{TiO}_{2}$ nanoparticles from 0 wt. $\%$ to 1.0 wt. $\%$. U4 membrane with higher hydrophilicity has higher attraction towards water which allows the water droplets to spread out on the membrane surface and pass through the pore spontaneously. Consequently increment of $\mathrm{TiO}_{2}$ nanoparticles causes an increase of macrovoid formation and porosity, leading to an increase of pure water permeability.

\subsection{Effect of Pre-treatment on Permeate Flux and Oil Rejection Rate}

The permeate flux of pre-treatment, M1 membrane under 2 bar is presented in Figure 7. The permeate flux declines drastically from 123.29 $\mathrm{LMH}$ to 86.30 $\mathrm{LMH}$ at the first ten minutes. The permeate flux continuously reduces to 30.44 LMH throughout the filtration process in a duration of 135 minutes. The reduction of flux can be explained by the occurrence of membrane fouling which requires to undergo a cleaning process. 
Besides, when compared with the pure water flux of M1 membrane, the flux decreases from 1104.09 LMH to 30.44 LMH. This phenomenon is caused by the accumulation of oil droplets on the membrane surface, resulting in an addition of transport resistance for water to oil permeate as well as the reduction in permeate flux.

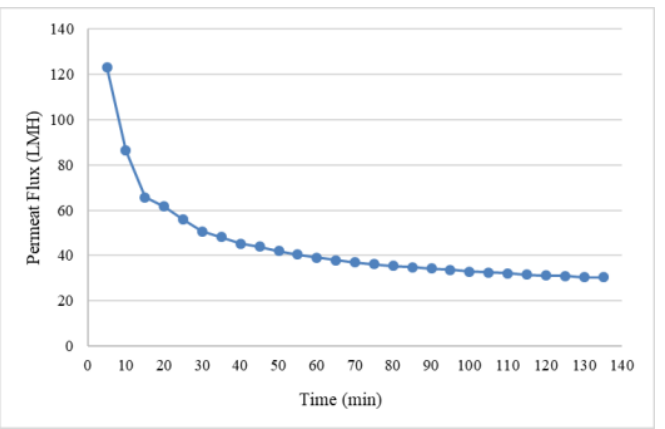

Figure 7 Permeate flux of M1 membrane against time under 2 bar

For the oil rejection, the initial oil concentration of the synthetic produced water is $556.33 \mathrm{mg} / \mathrm{L}$, whereas the oil content of wastewater after MF process is $265.11 \mathrm{mg} / \mathrm{L}$ as shown in Table 5. Therefore, the calculated oil removal rate is only $52.35 \%$.

Table 5 Oil removal analysis on M1 membrane

\begin{tabular}{|c|c|c|}
\hline \multicolumn{2}{|c|}{ Oil Concentration (mg/L) } & \multirow{2}{*}{$\begin{array}{l}\text { Oil } \\
\text { Removal } \\
(\%)\end{array}$} \\
\hline $\begin{array}{l}\text { Feed } \\
\text { Solution }\end{array}$ & MF Permeate & \\
\hline 556.33 & 265.11 & 52.35 \\
\hline
\end{tabular}

\subsection{Effect of $\mathrm{TiO}_{2}$ Concentration and Transmembrane Pressure on Permeate Flux}

Based on Figure 8, for U1 membrane without $\mathrm{TiO}_{2}$ additive, the permeate flux increases from 45.66 $\mathrm{LMH}$ at a transmembrane pressure of 3 bar to
$50.23 \mathrm{LMH}$ at a transmembrane pressure of 6 bar. Meanwhile, for U4 membrane with $1.0 \quad$ wt.\% $\quad \mathrm{TiO}_{2}$ nanoparticle, the permeate flux also raises from $46.80 \mathrm{LMH}$ at 3 bar to 55.25 LMH at 6 bar. The bar graphs indicate that higher pressure exerts higher force that allow more wastewater to flow through respective membrane, leading to an increase of permeate flux with greater pressure.

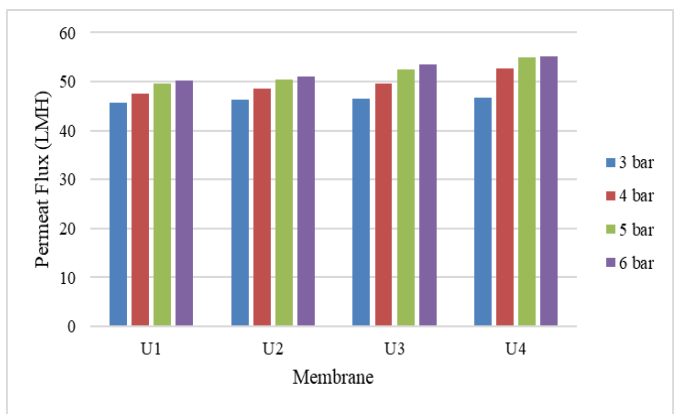

Figure 8 Permeate Flux of U1, U2, U3, U4 Membranes at 90 minutes under different transmembrane pressures

\subsection{Effect of $\mathrm{TiO}_{2}$ Concentration and Transmembrane Pressure on Oil Rejection Rate}

The oil rejection rate of each membrane under different pressure is presented in Figure 9. At the transmembrane pressure of 3 bar, the oil removal rate exhibits a relatively constant trend but the oil removal rate increases slightly from $89.24 \%$ for U1 to $95.71 \%$ for U4. The overall oil rejection which is the rejection rate for combined MF and UF processes thereby increases from $94.87 \%$ for U1 to $97.96 \%$ for U4. The slight improvement is attributed to the enhanced hydrophilicity coupled with the increase in pore diameter upon increment of highly hydrophilic additive [7].

However, at the transmembrane pressure of 4 bar, the line graph shows an opposite trend when compared with 
the trend at the transmembrane pressure of 3 bar. The oil removal rate declines from $92.64 \%$ for U1 to 85.94 $\%$ for U4. Hence, the overall oil rejection rate also decreases from $96.49 \%$ for U1 to $93.30 \%$ for U4. The main reason contributed to this abnormal phenomenon is human error. The solvent layer containing oil droplets was not completely evaporated, whereby the measurement of oil concentration might not only include residual oil but also the solvent.

At the transmembrane pressures of 5 bar and 6 bar, both of the oil removal trends are similar with the increasing trend at 3 bar. The oil removal rate of UF membranes and the overall oil rejection rates increases with the addition of $\mathrm{TiO}_{2}$ nanoparticles. It is observed that most of the membranes illustrate the promising oil rejection performances, where at least $82.34 \%$ oil rejection can be achieved. The highest overall oil removal rate can reach as high as $97.96 \%$.

By comparing the oil removal rate for different transmembrane pressures, the oil rejection is slightly reduced from 3 bar to 6 bar. By considering the permeate flux and oil rejection, it is evidenced that PES membrane prepared by $1.0 \mathrm{wt} \%$ additive is the optimum membrane to be used in UF process at the transmembrane pressure of 3 bar due to moderate permeate flux and excellent oil removal greater than $97 \%$.

\subsection{Effect of Membrane Cleaning on Flux Recovery Ratio (FRR)}

The recovery ratio of the fouled M1 membrane after cleaning by $\mathrm{NaOH}$ solution with different concentration and immersing duration is shown in Figure 10. It is noticeable that most of the flux recovery ratio are generally low as the best recovery result of 52.18
$\%$ is just slightly higher than $50 \%$ after cleaning with $1.0 \mathrm{M} \mathrm{NaOH}$ solution.
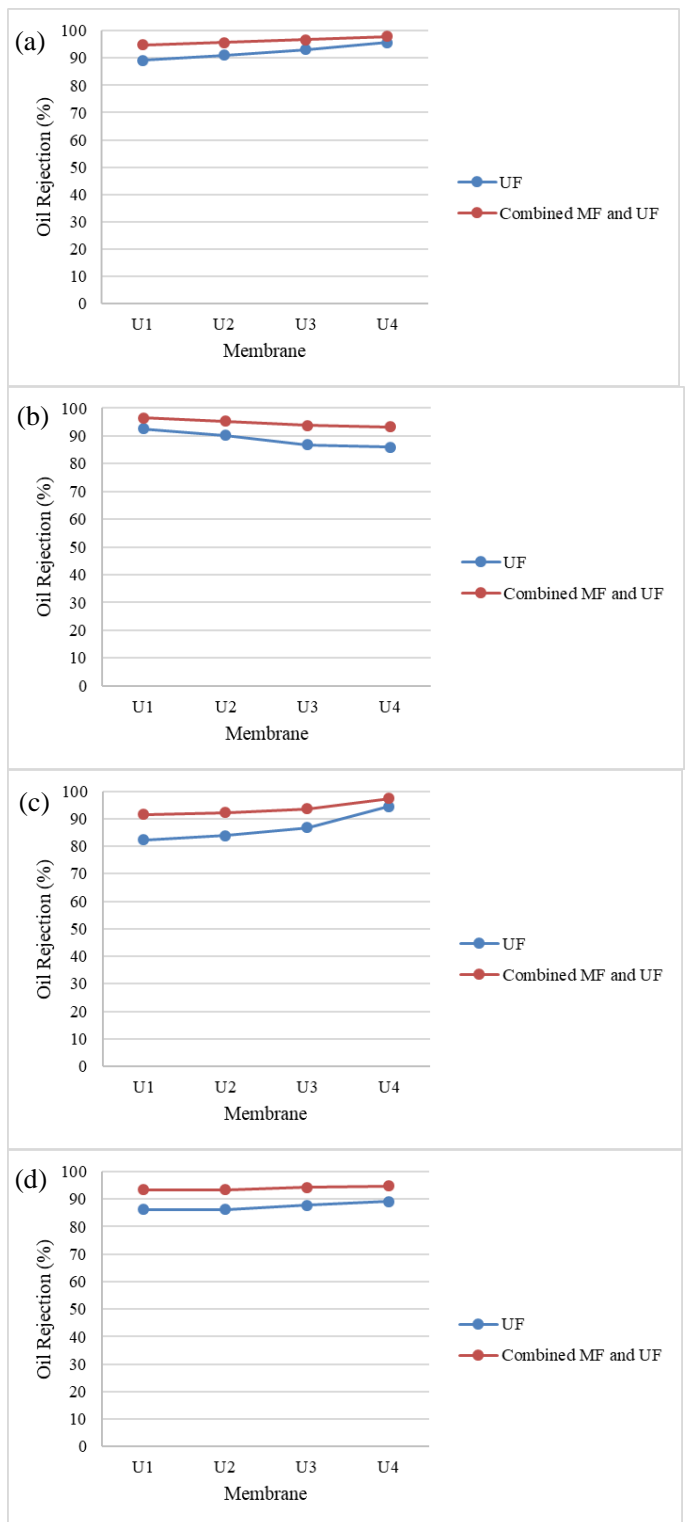

Figure 9 Oil rejection of U1, U2, U3 and U4 membranes under different pressures (a) 3 bar, (b) 4 bar, (c) 5 bar, (d) 6 bar

For the basic aqueous solution at a lower concentration of $0.1 \mathrm{M}$, the flux recovery ratio is lower than $20 \%$. According to Figure 10, the recovery performances exhibit similar trends between each other. It can be concluded that the flux recovery ratio increases with prolonged immersing 
duration and higher concentration of $\mathrm{NaOH}$ solution.

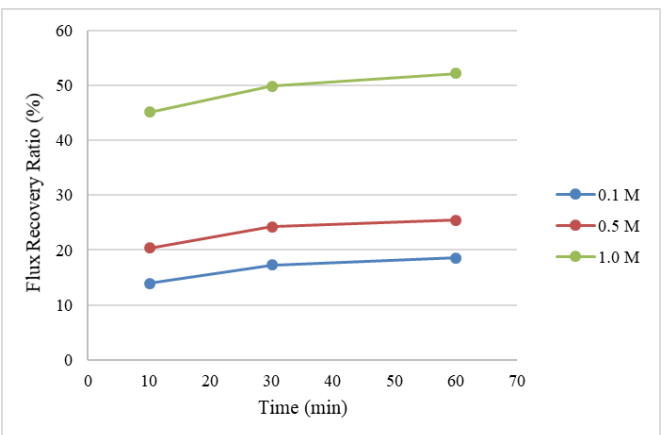

Figure 10 Flux recover ratios of M1 membrane after cleaning with different concentrations of $\mathrm{NaOH}$ solution

The results from membrane cleaning are coincided with other research, which reported that the recovery after washing by $\mathrm{NaOH}$ solution is low because the basic solution is not effective in removal of oil droplets within the membrane pores [3]. By employing $\mathrm{NaOH}$ solution as the cleaning agent, the oil droplets deposited on the surface of the membrane can be eliminated and the cake layer formed on the surface reduced slightly. However, the irreversible fouling cannot be easily treated by $\mathrm{NaOH}$ solution but intense chemical or thermal treatment should be applied. Therefore, this finding suggested that the cleaned M1 membranes are not suitable to be reused as $\mathrm{NaOH}$ solution is not sufficient to remove all the foulants and to let the fouled membranes recovered back to the original pure water flux.

\subsection{CONCLUSIONS}

Throughout the research, the treatment of synthetic produced water using hybrid membrane processes was initiated by combining microfiltration as pre-treatment and ultrafiltration with different concentrations of $\mathrm{TiO}_{2}$ nanoparticles ranging from $0 \mathrm{wt} . \%$ to 1.0 wt.\%. The fabricated membranes were characterized by SEM, EDX, FTIR and permeability tests. The SEM cross section micrographs showed that all membranes comprised of dense top finger-like layers and porous spongy support layers. U4 membrane surface contained the highest number of white particles with larger size due to the agglomeration of nanoparticles. From the FTIR and EDX analyses, the chemical composition of fabricated membranes was in accordance with the composition of prepared dope solution, but the weight percent of $\mathrm{Ti}$ element was slightly different due to the statistical error. The increase in $\mathrm{TiO}_{2}$ nanoparticles enhance the pore formation, porosity and pure water permeability due to improved hydrophilicity. In terms of membrane performance, the permeate flux of MF and UF membranes declined with time, whereas the permeate flux of UF membrane increased with the increase of $\mathrm{TiO}_{2}$ nanoparticles and transmembrane pressure. Besides, the oil removal rate after MF process was only $52.35 \%$, whereas the oil rejection efficiency using UF process was in the range between $82.34 \%$ and $95.71 \%$. Overall, the oil removal rate using the hybrid membrane processes could achieve as high as $97.96 \%$. Based on the results, PES membrane incorporated with $1.0 \mathrm{wt} . \%$ was found to be the most promising membrane since it exhibited the best separation performance in oil removal at a transmembrane pressure of 3 bar. The best recovery rate $(52.18 \%)$ after the membrane cleaning process was achieved using $1.0 \mathrm{M} \mathrm{NaOH}$ solution. Nevertheless, individual $\mathrm{NaOH}$ solution was proved to be not sufficient to overcome the fouling issue. 


\section{ACKNOWLEDGEMENT}

The authors would like to acknowledge Universiti Tunku Abdul Rahman, especially the Chemical Engineering Department and i-Chem Solution Sdn. Bhd. for the support throughout this project.

\section{REFERENCES}

[1] Jamaly, S., Giwa, A. and Hasan, S.W. $2015 . \quad$ Recent Improvements in Oily Wastewater Treatment: Progress, Challenges, and Future Opportunities. Journal of Environmental Sciences. 37: 1530.

[2] Han, L., Tan, Y. Z., Netke, T., Fane, A. G. and Chew, J. W. 2017. Understanding Oily Wastewater Treatment via Membrane Distillation. Journal of Membrane Science. 539: 284294.

[3] Masoudnia, K., Raisi, A., Aroujalian, A. and Fathizadeh, M. 2014. A Hybrid Microfiltration/ultrafiltration Membrane Process for Treatment of Oily Wastewater. Desalination and Water Treatment. 55(4): 901-912.

[4] Igunnu, E. and Chen, G. 2012. Produced Water Treatment Technologies. International Journal of Low-Carbon Technologies. 9(3): 157-177.

[5] Yu, L., Han, M. and He, F. 2017. A Review of Treating Oily Wastewater. Arabian Journal of Chemistry. 10: S1913-S1922.

[6] Križan Milić, J., Murić, A., Petrinić, I. and Simonič, M. 2013. Recent Developments in Membrane Treatment of Spent Cutting-oils: A Review. Industrial \& Engineering
Chemistry Research. 52(23): 7603-7616.

[7] Ong, C., Lau, W., Goh, P., Ng, B. and Ismail, A. 2013. Preparation and Characterization of PVDF-PVP-TiO2 Composite Hollow Fiber Membranes for Oily Wastewater Treatment Using Submerged Membrane System. Desalination and Water Treatment. 53: 1213-1223.

[8] Wang, P. and Chung, T.S. 2015. Recent Advances in Membrane Distillation Processes: Membrane Development, Configuration Design and Application Exploring. Journal of Membrane Science. 474: 3956.

[9] Hafidi, A., Pioch, D., Teyssier, M. L. and Ajana, H. 2004. Influence of Oil Conditioning on the Permeate Flux and Cake Properties during Microfiltration of Lampante Olive Oil. European Journal of Lipid Science and Technology. 106(3): 152-159.

[10] Zhu, Y., Wang, D., Jiang, L. and Jin, J. 2014. Recent Progress in Developing Advanced Membranes for Emulsified Oil/Water Separation. NPG Asia Materials. 6(5).

[11] DiGiano, F. 2001. Laboratory Tests of New Membrane Materials. Denver, CO: AWWA Research Foundation and the American Water Works Association.1-5.

[12] Song, L. and Tay, K. 2010. Advanced Membrane Fouling Characterization in Full-scale Reverse Osmosis Processes. Membrane and Desalination Technologies. 13: 101-134.

[13] Sadeghi, I., Aroujalian, A., Raisi, A., Dabir, B. and Fathizadeh, M. 2013. Surface Modification of Polyethersulfone Ultrafiltration 
Membranes by Corona Air Plasma For Separation of Oil/Water Emulsions. Journal of Membrane Science. 430: 24-36.

[14] Huang, J., Zhang, K., Wang, K., Xie, Z., Ladewig, B. and Wang, H. 2012. Fabrication of Polyethersulfone-mesoporous Silica Nanocomposite Ultrafiltration Membranes with Antifouling Properties. Journal of Membrane Science. 423: 362370.
[15] Woodard, F. 2001. Industrial Waste Treatment Handbook. Elsevier.

[16] Yuan, Z. and Dan-Li, X. 2008. Porous PVDF/TPU Blends Asymmetric Hollow Fiber Membranes Prepared with the Use of Hydrophilic Additive PVP (K30). Desalination. 223(13): $438-447$. 